\title{
Re: Results of a randomized trial of treatment modalities in patients with low or early-intermediate risk prostate cancer (PREFERE trial)
}

\author{
Andreas Boehle ${ }^{1,2}\left(\right.$ Frank Kahmann $^{3} \cdot$ Thomas Oliver Henkel $^{3} \cdot$ Joerg Zimmermann ${ }^{4} \cdot$ Stefan Machtens ${ }^{5}$
}

Received: 21 November 2020 / Accepted: 11 December 2020 / Published online: 28 January 2021

(c) The Author(s) 2021

\section{Abstract}

The authors of this "Letter to the Editors" express their major concern about selective and biased reporting in this paper.

$\begin{array}{ll}\text { Abbreviations } \\ \text { PSI } & \text { Permanent seed implantation } \\ \text { RP } & \text { Radical prostatectomy } \\ \text { EBRT } & \text { External beam radiation therapy } \\ \text { AS } & \text { Active surveillance } \\ \text { CTCAE } & \begin{array}{l}\text { Common terminology criteria for adverse } \\ \text { events }\end{array}\end{array}$

Sir,

It is with concern that we read this publication.

In the abstract, the authors conclude on "an increased toxicity related to (PSI)", neglecting the results as "treatmentrelated acute grade 3 toxicity was reported in $3 \mathrm{RP}$ patients and 2 PSI patients". Selectively emphasizing side effects of one treatment whilst neglecting even higher toxicity in another does not mirror scientific neutrality.

Wiegel, T., Albers, P., Bartkowiak, D. et al. Results of a randomized trial of treatment modalities in patients with low or early-intermediate risk prostate cancer (PREFERE trial). $J$ Cancer Res Clin Oncol (2020). https://doi.org/10.1007/s00432-020-03327 -2 .

This comment refers to the article available online at https://doi. org/10.1007/s00432-020-03327-2.

Andreas Boehle

boehle@urologie-bad-schwartau.de

Frank Kahmann

Dr.Kahmann@t-online.de

Thomas Oliver Henkel

Dr.Henkel@gmx.de

Joerg Zimmermann

joergzimmermann@me.com

Stefan Machtens

Stefan.Machtens@mkh-bgl.de
The results show that most patients accepted AS as a treatment strategy (84\%). However, of all radical therapy options, PSI was the most accepted one (PSI 65\%; RP 49\%; EBRT 44\%).

Furthermore, the lowest switch-over from one randomized radical therapy to another therapy was in PSI (change of randomized therapy from PSI 11\%, EBRT 19\%, and RP 19\%). These data emphasize the relatively high acceptance of patients to PSI, but unfortunately remains uncommented by the authors.

CTCAE acute toxicity ( $<12$ months) grade 3 occurred in five patients, three in RP, and two in PSI, respectively. Figure 3 a shows a higher percentage of overall toxicity (grades 1-3), a higher percentage of grade 3 toxicity, and a higher percentage of grade 2 toxicity in EBRT as compared to PSI.

CTCAE late toxicity (at 12 months) grade 3 occurred in 28 patients, 15 in RP, 9 in PSI, and 4 in EBRT, respectively. Figure $3 \mathrm{~b}$ of the original article shows a higher percentage of overall toxicity (grades 1-3), a higher percentage of grade 3 toxicity, a higher percentage of grade 2 toxicity, and a higher percentage of grade 1 toxicity in EBRT as compared to PSI. Neglecting their own data, the authors state that "Interestingly, the preliminary data suggest an increased risk of toxicity after PSI compared with EBRT." This statement

1 Department of Urology, University of Luebeck, Ratzeburger Allee 160, Luebeck 23562, Germany

2 Department of Urology, HELIOS Agnes-Karll Hospital, Am Hochkamp 21, Bad Schwartau 23611, Germany

3 MVZ Ihre Urologen GbR, Britzer Damm 63, 12347 Berlin, Germany

4 Praxiszentrum Alstertal, Heegbarg 2, 22391 Hamburg, Germany

5 Department of Urology, Marien-Krankenhaus, Dr.-Robert-Koch-Straße 18, 51465 Bergisch Gladbach, Germany 
is heavily biased toward EBRT and not supported by the facts.

The authors state that the study review revealed more quality-assurance issues in PSI than in RP and EBRT. This statement is not proven by any data given in the results. Furthermore, the authors neglect that in PSI, other than in EBRT and RP, a post-therapy quality control within 8 weeks is possible by so-called post-planning calculation. Notwithstanding the fact that post-planning documentation was missing/incomplete in 19\%, an existing post-procedural quality-assurance in PSI cannot be compared to no postprocedural quality assurance at all, as in RP and EBRT.

Finally, with no data whatsoever reported on oncological outcomes, the authors state without proof that "oncological outcomes after PSI are unlikely to become superior to EBRT at the current state." Again, we feel this statement is not supported by any facts and heavily biased toward EBRT.

Sincerely,

Andreas Boehle.

Frank Kahmann.

Thomas Oliver Henkel.

Joerg Zimmermann.

Stefan Machtens.

Funding Open Access funding enabled and organized by Projekt DEAL.

\section{Compliance with ethical standards}

Conflict of interest The authors declare that they have no conflict of interest.

Ethical approval All procedures performed in studies involving human participants were in accordance with the ethical standards of the institutional and/or national research committee and with the 1964 Helsinki declaration and its later amendments or comparable ethical standards. For this type of study, formal consent was not required.

Open Access This article is licensed under a Creative Commons Attribution 4.0 International License, which permits use, sharing, adaptation, distribution and reproduction in any medium or format, as long as you give appropriate credit to the original author(s) and the source, provide a link to the Creative Commons licence, and indicate if changes were made. The images or other third party material in this article are included in the article's Creative Commons licence, unless indicated otherwise in a credit line to the material. If material is not included in the article's Creative Commons licence and your intended use is not permitted by statutory regulation or exceeds the permitted use, you will need to obtain permission directly from the copyright holder. To view a copy of this licence, visit http://creativecommons.org/licenses/by/4.0/.

Publisher's Note Springer Nature remains neutral with regard to jurisdictional claims in published maps and institutional affiliations. 